\title{
Specialistische ondersteuning in de basiszorg voor jeugd: verbindingen maken in het sociale domein
}

\author{
Meinou H. C. Theunissen · J.J. (Anna) Dijkshoorn · Mariska Klein Velderman
}

Published online: 13 November 2018

(C) Bohn Stafleu van Loghum is een imprint van Springer Media B.V., onderdeel van Springer Nature 2018

\begin{abstract}
Samenvatting Sinds de nieuwe Jeugdwet in werking is getreden zijn gemeenten verantwoordelijk voor alle vormen van jeugdhulp. Dit betekent dat zij zorg moeten dragen voor tijdige signalering en behandeling van psychische problematiek bij kinderen. Huisartsen en jeugdartsen zijn bij psychische klachten van kinderen vaak het eerste aanspreekpunt.

Op basis van de ervaringen met het nieuwe stelsel blijkt dat de samenwerking in het sociale domein (school, jeugd-ggz, sociaal wijkteam, huisarts, enzovoort) niet optimaal is en dat er zorgen zijn over de vraag of kinderen de passende zorg geboden wordt die ze nodig hebben. Om artsen te helpen een sterke poortwachtersrol te vervullen, nemen steeds meer gemeenten het initiatief (jeugd)artsen te laten ondersteunen door een specialist op het gebied van jeugd (-ggz) aan te stellen. Door middel van deze initiatieven wordt kennis over psychische problemen vanuit specialistische zorg ingezet in de basiszorg.

Dit artikel geeft een overzicht van verschillende pilots, waarbij een specialist op het gebied van jeugd is aangesteld om de uitvoeringspraktijk van de (jeugd)gezondheidszorg te versterken en integraal de juiste zorg te kunnen bieden. Semigestructureerde interviews met contactpersonen van de betrokken organisaties werden ingezet en gevonden documentatie werd gebruikt om de pilots te beschrijven en de ervaringen in kaart te brengen. Een overzicht van zeven initiatieven biedt hulpverleners en beleidsmakers de mogelijkheid om van elkaar te leren en de samenwerking binnen het sociale domein te versterken.
\end{abstract}

Dr. M. H. C. Theunissen · J. Dijkshoorn · Dr. M. Klein

Velderman ( $\square)$

Afdeling Child Health, TNO, Leiden, Nederland

mariska.kleinvelderman@tno.nl
Trefwoorden Jeugdwet · kinderen · ggz · samenwerking $\cdot$ sociaal domein $\cdot$ basiszorg $\cdot$ specialistische zorg

\section{Specialists supporting preventive youth healthcare: towards increased integrated care within the social domain}

Abstract The municipalities are responsible for all youth care services since the implementation of the new Youth Act (2015). Consequently, they are responsible for early detection and treatment of psychosocial problems in children. General Practitioners (GP's) and preventive child healthcare professionals are the first port of call for psychosocial problems in children. Based on the experiences with the new system it appears that there is room for improvement regarding collaboration within the social domain (school, youth mental healthcare, social team, GP). There are concerns that children do not receive the care they need. In order to support doctors to fulfill their gatekeepers role, increasingly municipalities appoint youth mental health specialists at the preventive services.

This article describes several initiatives in which a youth mental health specialist is appointed to strengthen preventive youth healthcare and to offer integrally the care that children need. Semi structured interviews were held with the contact persons of organizations concerned. These interviews and relevant documentation were used to describe the initiatives and to inventory experiences with these initiatives. The resulting overview of seven initiatives may offer healthcare professionals and policymakers the possibility to learn from each other and to strengthen the collaboration within the social domain.

Keywords Youth Act · Children · Mental health · Collaboration $\cdot$ Social domain $\cdot$ Basic care $\cdot$ Specialist care 


\section{Kernpunten}

- Sinds de nieuwe Jeugdwet in werking is getreden zijn gemeenten verantwoordelijk voor het organiseren van passende jeugdhulp.

- De samenwerking in het sociale domein rond de jeugdhulp verloopt nog niet optimaal, waardoor kinderen niet altijd de zorg krijgen die ze nodig hebben.

- Steeds meer gemeenten stellen een specialist op het gebied van jeugd(-ggz) aan om huisartsen en jeugdartsen te ondersteunen bij hun poortwachtersrol.

- Dit artikel biedt een overzicht van verschillende pilots waarin een specialist op het gebied van jeugd is aangesteld om de (jeugd)gezondheidszorg te versterken.

\section{Inleiding}

\section{De nieuwe Jeugdwet: decentralisatie, transitie en transformatie}

Sinds de nieuwe Jeugdwet in januari 2015 in werking is getreden zijn gemeenten verantwoordelijk voor alle vormen van psychosociale zorg aan jeugdigen: de zogenaamde 'decentralisatie' van alle jeugdhulp. Dit betekent dat gemeenten verantwoordelijk zijn voor zowel de basiszorg als de specialistische zorg. De overheveling van jeugdzorg van de provincies naar gemeenten wordt ook aangeduid als 'transitie'. Tot de basiszorg (eerstelijnszorg) rekenen we alle vormen van lichte ondersteuning en begeleiding waarvoor geen verwijzing nodig is. Onder de basiszorg vallen de huisartsenzorg, jeugdgezondheidszorg (JGZ), thuiszorg, Centra voor Jeugd en Gezin (CJG's), (sociale) wijkteams en opvoedondersteuning [1]. Binnen deze basiszorg staan signalering, lichte, vroegtijdige en vrij toegankelijke hulp en ondersteuning centraal, en kan waar nodig intensievere hulp worden ingeroepen [2]. Onder specialistische of intensievere zorg verstaan we hulp waarvoor specifieke deskundigheid is vereist. Het gaat dan onder andere om hulp aan kinderen met een psychiatrische stoornis, ernstige gedragsproblemen en complexe of meervoudige problematiek. Deze specialistische zorg wordt geboden door instellingen voor kinder- en jeugdpsychiatrie (geestelijke gezondheidszorg voor jeugd; jeugd-ggz), specialistische jeugdzorg en zorg voor jeugd met een licht verstandelijke beperking (jeugd-lvb) [3]. Het betreft niet vrij toegankelijke hulp waarvoor een verwijzing nodig is.

Naast een verschuiving in bestuurlijke en financiële verantwoordelijkheden moest er met de nieuwe Jeugdwet ook een inhoudelijke transformatie van het jeugdbeleid plaatsvinden. Centrale uitgangspunten van deze transformatie zijn 1) een focus op preven- tie (eigen kracht), 2) 'demedicalisering' (ontzorgen en normaliseren), 3) tijdig de juiste hulp op maat bieden om specialistische zorg te verminderen, 4) integrale hulp aan gezinnen volgens het uitgangspunt 'één gezin, één plan, één regisseur', en 5) meer ruimte en vermindering van regeldruk voor professionals.

Inmiddels zijn de eerste ervaringen met het nieuwe stelsel opgedaan en blijken er zorgen te zijn over de vraag of kinderen en jeugdigen de passende zorg geboden wordt die ze nodig hebben. De zorgen lijken zich toe te spitsen op de toegang tot en de kwaliteit van de jeugdhulp na de decentralisatie [2]. In de jeugd-ggz bestaat bijvoorbeeld de vrees dat bezuinigingen ten gevolge van de transitie en transformatie ertoe leiden dat kinderen niet de juiste zorg krijgen [3]. Al voor de transformatie was bekend dat van de jeugdigen voor wie jeugd-ggz-zorg passend lijkt gemiddeld genomen minder dan de helft daar gebruik van maakt [4]. Vooral voor specifieke groepen lijkt dit het geval - migrantenkinderen [5-7] en kinderen van laagopgeleide ouders [8] maken doorgaans minder gebruik van jeugd-ggz, terwijl in deze specifieke groepen zeker niet minder sprake is van psychische problemen $[9,10]$. De transformatie kan mogelijk aanknopingspunten bieden om kinderen vaker de juiste zorg te geven.

\section{Aansluiting van basiszorg op specialistische zorg}

Er lijkt dus een discrepantie te bestaan tussen de mate waarin psychische of psychosociale problemen gezien worden in de basiszorg en de mate waarin de specialistische zorg voor begeleiding hierbij wordt bereikt. Migrantenkinderen en kinderen van laagopgeleide ouders worden bijvoorbeeld in dezelfde mate gezien door JGZ, maar zijn toch ondervertegenwoordigd in de specialistische zorg. Mogelijk kunnen de decentralisatie en transformatie bijdragen aan meer aansluiting tussen basiszorg (en basisvoorzieningen) in het sociale domein (bijvoorbeeld school, JGZ, sociaal wijkteam, huisarts, enzovoort) enerzijds en specialistische zorg (bijvoorbeeld jeugd-ggz, specialistische jeugdzorg) anderzijds. Een betere aansluiting zou kunnen zorgen voor meer passende hulp waar nodig. Er zijn bewegingen in die richting en daarover gaat dit artikel.

Verschillende initiatieven zijn ontstaan om transformatiedoelstellingen 3 ('tijdig de juiste hulp op maat bieden') en 4 ('integrale hulpvormen te stimuleren') te realiseren en (kosten)effectievere jeugdhulp te organiseren. Steeds meer gemeenten kiezen er bijvoorbeeld voor om gespecialiseerde jeugdhulpverleners in te zetten bij basiszorginstellingen of basisvoorzieningen (zoals kinderopvang, onderwijs) [3]. Dit kunnen gedragswetenschappers (bijvoorbeeld psychologen of orthopedagogen) zijn, die worden gedetacheerd vanuit een jeugd-ggz of jeugdhulpinstelling en die worden ingezet ter ondersteuning van de huisarts, de JGZ, de school of het CJG. De (licht)specialistische hulp wordt 
dan geboden vanuit de eerste lijn, zonder dat een verwijzing naar specialistische zorg nodig is. De taken van deze gespecialiseerde jeugdhulpverleners zijn onder andere: kortdurende hulp bieden, consultatiefunctie voor andere hulpverleners en toeleiding naar passende zorg.

Vooral met de inzet van specialistische ondersteuning in de huisartsenzorg is geëxperimenteerd. Enerzijds gaat het om initiatieven onder de noemer praktijkondersteuner huisarts-jeugd ( $\mathrm{POH}$-jeugd). Het betreft een hbo- of wo-geschoolde professional met ervaring in de jeugd-ggz of kinder- en jeugdpsychiatrie. Het eerste project met de POH-jeugd begon in 2010. Het doel is vroegtijdig opsporen van psychosociale problemen in de eerste lijn en waar mogelijk kortdurend behandelen door de $\mathrm{POH}$-jeugd en indien noodzakelijk doorverwijzen naar specialistische zorg (de tweede lijn). Voor een overzicht zie Jonker en collega's [11].

Anderzijds gaat het bijvoorbeeld om een Gelders initiatief. Een jeugd-ggz-professional (specialistisch ondersteuner huisartsenzorg, $\mathrm{SOH}$ ) is op locatie bij huisartsen beschikbaar en kan laagdrempelig door de huisartsen worden ingeschakeld. De $\mathrm{SOH}$ richt zich op psychische screeningsdiagnostiek van jeugdigen, verwijst jeugdigen door en verleent soms ook zelf kortdurende psychologische behandelingen. Uit een evaluatie blijkt het succes: door de inzet van de $\mathrm{SOH}$ (voluit 'SOH-JGGZ') lijkt sneller de juiste hulp te worden ingezet. Huisartsenpraktijken met en zonder $\mathrm{SOH}$ werden met elkaar vergeleken. In de huisartsenpraktijken met $\mathrm{SOH}$ werd significant minder naar de ggz (vooral minder naar de generalistische basis-ggz) verwezen. Kinderen en ouders waren zeer tevreden, omdat ze snel en laagdrempelig terechtkonden bij een gespecialiseerde hulpverlener [12].

Ondanks deze initiatieven in de huisartsenzorg blijft de samenwerking tussen het sociale domein (school, JGZ, sociaal wijkteam, huisarts) en de specialistische zorg (jeugd-ggz) beperkt [12, 13]. Denk bijvoorbeeld aan deelname aan multidisciplinaire overleggen. Daarom worden JGZ-organisaties in sommige gemeenten door gemeenten gevraagd het voortouw te nemen in de samenwerking, om kinderen zo snel mogelijk naar de juiste hulp te leiden. JGZ-organisaties zijn een uitvoerder van de publieke gezondheidszorg van nul tot negentien jaar onder de Wet Publieke gezondheid. De JGZ geeft, net als huisartsen, aan hulp te kunnen gebruiken bij het signaleren en verwijzen van psychosociale en gezinsproblemen (persoonlijke communicatie).

\section{Huidige verkenning}

In dit artikel staat een inventarisatie centraal van initiatieven gericht op de inzet van een ondersteuner op het gebied van specialistische zorg voor jeugd(-ggz) binnen basiszorgvoorzieningen. Deze specialistische ondersteuner wordt vanuit de jeugdhulp of jeugd-ggz ingezet bij de basiszorgvoorzieningen. We gaan na welke initiatieven er zijn, en op welke manier deze initiatieven verbinding tussen basiszorg en specialistische tot stand proberen te brengen. Per initiatief wordt gekeken welke specialistische ondersteuner er wordt ingezet (bijvoorbeeld gezondheidszorgpsycholoog jeugd-ggz, medewerker jeugdhulp) en welke taken deze uitvoert (bijvoorbeeld kortdurende begeleiding, consultatie en advies, en toeleiding naar passende hulp). Ook brengen we de mate van samenwerking met het sociale domein in kaart. De inventarisatie sluit aan bij een door ZonMw gefinancierd project 'Inzet van de Specialistisch Ondersteuner Jeugd (SOJ) in de jeugdgezondheidszorg (JGZ)'. Dat project is gericht op de doorontwikkeling en evaluatie van de innovatieve SOH-werkwijze in de JGZ, gericht op het verbeteren van de samenwerking binnen het sociale domein (en omvat ook initiatief 6 en 7, zie onder het kopje 'Resultaten'). Om te kijken wat er specifiek of uniek is aan deze pilot en het bredere kader in beeld te brengen, is gezocht naar gelijksoortige initiatieven in Nederland. Dit artikel biedt een overzicht van deze verkenning en een beschrijving van de (eerste) ervaringen met deze nieuwe werkwijzen.

\section{Methode}

We hebben lopende of reeds afgeronde initiatieven gezocht via drie routes. Om te beginnen hebben we via Google (Scholar) gezocht. Hiernaast werden leden van de project- en klankbordgroepen, te weten onderzoekers van TNO, stafmedewerkers van twee JGZorganisaties, de projectleider SOJ van GGZ Karakter, vertegenwoordigers van GGD GHOR, V\&VN, NCJ en AJN gevraagd bekende gelijksoortige projecten aan te dragen. Ten slotte hebben we via het sneeuwbaleffect en een oproep op LinkedIn (28 april 2017; 1.386 views, 192 likes, 44 reacties, 26 keer gedeeld) aanvullende pilots gezocht.

Initiatieven werden geïncludeerd wanneer zij gericht waren op de inzet van een specialist op het gebied van jeugd ten aanzien van de psychosociale ontwikkeling en het psychisch functioneren, ter versterking van de basiszorg, en ten behoeve van een betere aansluiting op jeugdhulp. Het gaat om initiatieven die gestart waren of doorgang vonden sinds de stelselwijziging van januari 2015. Wanneer een specialist uitsluitend ter ondersteuning van de huisarts was aangesteld, zoals de veel voorkomende $\mathrm{POH}$-jeugd of de $\mathrm{SOH}$ (zie ook de inleiding), werd dit niet meegenomen in de inventarisatie. We hadden een bredere samenwerking in het sociale domein voor ogen. Betrokken organisaties van de initiatieven werden benaderd via e-mail. Zij werden gevraagd bij te dragen aan de verkenning en contactpersonen aan te dragen voor een telefonisch interview of om via e-mail een aantal vragen te beantwoorden. Medio 2017 vonden telefonische interviews en mailcontact plaats. Interviews en mailwisselingen waren (semi)gestructureerd rondom 
vragen over de inzet van de specialistisch ondersteuner jeugd. De volgende onderwerpen kwamen aan bod: 1) doelgroep en werkzaamheden van de hulpverlener en 2) samenwerking binnen het sociale domein. De gevonden documentatie is ook gebruikt om de initiatieven te beschrijven en de (eerste) ervaringen in kaart te brengen.

De opbrengsten zijn kwalitatief van aard en de antwoorden van de betrokkenen zijn op een exploratieve, beschrijvende wijze verwerkt. Hieronder zijn per initiatief de in documentatie en interviews genoemde ervaringen, resultaten en aandachtspunten beschreven.

\section{Resultaten}

Er zijn dertig initiatieven gevonden van specialistisch ondersteuners jeugd in het sociale domein. Drieëntwintig initiatieven zijn niet meegenomen in de inventarisatie omdat deze uitsluitend gericht waren op ondersteuning van de huisarts of omdat er geen voldoende duidelijke beschrijving van het initiatief beschikbaar was en/of via contactpersonen verkregen kon worden. De resterende zeven initiatieven zijn afkomstig uit vier verschillende Nederlandse provincies: Noord-Holland, Groningen, Flevoland en Gelderland. Hieronder vindt $\mathrm{u}$ een korte beschrijving per initiatief.

\section{Beschrijving per initiatief}

\section{Noord-Holland (Haarlem en Zandvoort) - CJG POH Jeugd}

In de gemeenten Haarlem en Zandvoort wordt een $\mathrm{POH}$-jeugd ingezet in de huisartsenpraktijken. Bij dit initiatief is de $\mathrm{POH}$ in dienst van het CJG, en heeft de inzet van deze $\mathrm{POH}$ als doel het domein van de huisartsenzorg en het sociale domein met elkaar te verbinden. De kerntaken van de $\mathrm{POH}$ zijn de volgende drie: begeleiding en kortdurende behandeling van ouders en jeugdigen, consultatiefunctie voor huisartsen en andere praktijkprofessionals, en vraagverheldering voor ouders/opvoeders en kinderen om door te kunnen verwijzen naar passend zorgaanbod. De mate van structureel overleg en samenwerkingsafspraken met partners uit het sociale domein varieert, afhankelijk van de praktijk waar de $\mathrm{POH}$ werkzaam is, hoe lang de $\mathrm{POH}$ werkzaam is bij de betreffende praktijk en van de vragen van cliënten ofwel verschillen in de aard van de populatie van de huisarts.

\section{Groningen - jeugd-ggz-medewerkers}

In de provincie Groningen zijn bij verschillende huisartsenpraktijken en CJG- of lokale teamlocaties jeugdggz-medewerkers ingezet, vaak gedetacheerd vanuit gespecialiseerde ggz-instellingen. Dit zijn meestal gespecialiseerde verpleegkundigen of gedragswetenschappers. Een dergelijke jeugd-ggz-medewerker heeft als taak het bieden van passende behandelingen en laagdrempelige consultatie door huisartsen en lokale teams, en het ondersteunen van de huisarts bij verwijzingen naar een lokale hulpverlener of goed onderbouwd verwijzen naar de tweede lijn. De jeugdggz-medewerker is de verbindende factor tussen de huisarts en het CJG/JGZ- of lokale team. Voor casuïstiek waarbij verschillende instanties betrokken zijn kan deze jeugd-ggz-medewerker namens de huisarts multidisciplinaire overleggen van de teams bijwonen en op die manier de verbindende schakel zijn. Ook overlegt deze medewerker met andere betrokken partijen, zoals scholen, JGZ en maatschappelijk werk.

De eerste ervaringen laten zien dat de grootste groep die door de huisarts wordt aangemeld bij de jeugd-ggz-medewerker tussen de zeven en achttien jaar oud was. Met de inzet van de jeugd-ggz-medewerker werd slechts een klein gedeelte van jeugdigen doorverwezen naar een instelling voor specialistische hulp, de overige jeugdigen werden laagdrempelig dicht bij huis geholpen. Punten van aandacht die naar voren kwamen in de evaluatie zijn efficiënte en goede dossiervorming door de jeugd-ggz-medewerker en het op de juiste wijze delen van informatie over de jeugdige met andere hulpverleners [14].

\section{Flevoland (Almere) - medewerkers jeugdhulp}

In de gemeente Almere zijn op verschillende locaties van de JGZ Almere medewerkers jeugdhulp ingezet. Deze werkten voorheen bij de afdeling Toegang van Bureau Jeugdzorg en zijn nu in dienst bij JGZ Almere. De medewerkers jeugdhulp hebben als taken gekregen onder andere het analyseren van de hulpvraag van ouders en jeugdigen bij complexe opvoedvragen, het bieden van kortdurende ondersteuning door middel van gesprekken met jeugdigen, het ondersteunen van andere wijkwerkers op het gebied van jeugd bij complexe vraagstukken, het in samenspraak met betrokkenen komen tot een passend hulpverleningsaanbod en het onderzoeken van middelzware zorgmeldingen van de politie en waar nodig het inzetten van hulpverlening. De medewerkers jeugdhulp nemen deel aan het multidisciplinaire overleg van JGZ Almere en sluiten aan bij betrokken zorgteams van bijvoorbeeld het voortgezet speciaal onderwijs. Incidenteel vindt er ook overleg plaats met jeugdhulpaanbieders, scholen en andere professionals voor individuele casuïstiek.

\section{Gelderland (Nijmegen) - jeugdspecialist}

In de gemeente Nijmegen wordt het project 'De school als vindplaats' uitgevoerd. Aan elke school in het primaire onderwijs is een jeugdspecialist verbonden. Door dit initiatief is er laagdrempelig een specialist aanwezig op school. De taken van deze specialist zijn onder andere het aanbieden van consultatie en advies aan ouders, leerkrachten en andere hulpverleners, het toepassen van kortdurende preventieve interventies, en het organiseren en faciliteren van een warme overdracht naar beschikkingszorg. Indien nodig neemt de jeugdspecialist deel aan het multidisciplinaire overleg van het ondersteuningsteam van de school, waarin de 
jeugdarts en de school (maatschappelijk werk, interne begeleider) zitting hebben. Ook vindt er incidenteel overleg plaats met de GGD en het sociale wijkteam.

\section{Gelderland (Epe) - gezondheidszorgpsycholoog}

In de gemeente Epe wordt een gezondheidszorg (gz)psycholoog ingezet bij de huisartsen. Deze gz-psycholoog is in dienst van het CJG en heeft als taak het versterken van de samenwerking tussen de huisartsen en het CJG. Deze gz-psycholoog is gericht op het bieden van kortdurende behandeling, enkelvoudige diagnostiek, bereikbaar zijn voor consultatie door de huisarts en toeleiding naar passende (jeugd)hulp. Er vindt geregeld overleg plaats tussen de gz-psycholoog en collega's van het CJG, en met partners zoals het onderwijs en zorgaanbieders voor jeugdhulp en jeugd-ggz.

6. Gelderland (Nijmegen) - specialistische ondersteuner jeugd-ggz

In de gemeente Nijmegen wordt op twee jeugdgezondheidszorglocaties een SOJ ingezet (onderdeel van het ZonMw-onderzoek dat aanleiding was voor de onderhavige verkenning). Deze SOJ'ers (ervaren specialistisch ondersteuners huisarts, SOH) zijn gz-psychologen die gedetacheerd zijn vanuit de ggz, betaald worden door de gemeente en werkzaam zijn bij de JGZ. De functie wordt aangeduid als 'specialistisch ondersteuner' omdat binnen deze functie ondersteuning wordt geboden aan de JGZ vanuit de specialistische ggz. Doel is om de expertise op het terrein van de jeugd-ggz in de eerste lijn te versterken en de indicatiestelling te verbeteren voor verwijzing naar specialistische zorg wanneer dat nodig is. Tot de taken van deze SOJ behoren consultatie door de jeugdarts en -verpleegkundigen, bijdragen aan screeningsdiagnostiek, triage of probleemverheldering en toeleiding naar passende zorg. De SOJ'ers nemen niet deel aan structureel overleg met partners in het sociale domein. Wel zijn er duidelijke werkafspraken met de JGZ en hebben de SOJ'ers per cliënt contact met relevante praktijkprofessionals (bijvoorbeeld uit de jeugdhulp, ggz). De SOJ'ers hebben een kleine aanstelling (wekelijks 1 uur). De eerste ervaringen geven aan dat ze in deze tijd vooral ondersteuning aan de jeugdarts en -verpleegkundigen bieden door middel van advies, en een of twee gesprekken met de ouder(s) en/of het kind. Er is geen tijd voor kortdurende hulp aan de cliënten zelf. Ondanks de kleine aanstellingen zijn zowel de SOJ'ers als de jeugdartsen en -verpleegkundigen zeer tevreden over de samenwerking.

7. Gelderland (Renkum) - gedragswetenschapper jeugd

In Renkum zijn door de gemeente twee gedragswetenschappers jeugd aangesteld (eveneens onderdeel van het genoemde ZonMw-onderzoek). De gedragswetenschappers zijn in dienst van de GGD, gedetacheerd bij de gemeente, en werken op twee GGDlocaties en op het gemeentekantoor. Doel is kinde- ren tot achttien jaar laagdrempelig en snel goede hulp te bieden op het gebied van ontwikkeling, gedrag en opvoeding. De voornaamste taken van deze gedragswetenschapper zijn ondersteuning bieden met kortdurende gesprekken, consultatie door huisartsen en jeugdartsen, en begeleiden naar passende zorg. Er vindt overleg plaats met de coördinator van het sociale team. De eerste ervaringen geven aan dat het fijn is dat er een ruime aanstelling is. Twee gedragswetenschappers hebben samen 1 fte ter beschikking, wat het mogelijk maakt om ook kortdurende ondersteuning te bieden aan cliënten (ouders, kinderen, jeugdigen). De meeste cliënten worden door de huisarts naar de gedragswetenschapper verwezen en niet door de JGZ. Punt van aandacht is dat de gedragswetenschappers nog niet voldoende zichtbaar lijken voor de JGZ.

\section{Beschouwing}

Dit artikel betreft een inventarisatie van initiatieven gericht op de inzet van een specialistisch ondersteuner op het gebied van jeugd(-ggz), ten behoeve van kennis over psychische problemen vanuit de specialistische zorg, binnen de basiszorg en basisvoorzieningen in het sociale domein. We hebben zeven initiatieven uit vier Nederlandse provincies beschreven. Het betreft bij CJG's aangestelde POH'ers jeugd (Haarlem/Zandvoort) of gz-psychologen (Epe) werkzaam in huisartsenpraktijken. Ook gaat het om jeugd-ggzmedewerkers (Groningen en Nijmegen), medewerkers jeugdhulp (Almere) of gedragswetenschappers (Renkum) werkzaam bij het sociale wijkteam of de JGZ en een jeugdspecialist werkzaam in het onderwijs (Nijmegen). Al deze professionals uit de specialistische zorg bieden consultatie en advies aan professionals in basis(zorg)voorzieningen en dragen bij aan de toeleiding naar passende hulp. De meeste professionals bieden ook kortdurende begeleiding voor jeugdigen en ouders. De mate van verbinding met het sociale domein bleek verschillend. In alle initiatieven vindt er incidenteel casuïstiekoverleg plaats tussen de jeugdspecialist en sociale partners. In sommige initiatieven vindt er ook structureel overleg plaats, waarbij een specialistische ondersteuner deelneemt aan multidisciplinaire overleggen, zoals zorgteams in het onderwijs (het Nijmeegse initiatief 4). Er bleken nog nauwelijks samenwerkingsafspraken te zijn gemaakt tussen de specialistisch ondersteuners en partners uit de basis- of specialistische zorg buiten de eigen organisaties.

Een totaal van zeven initiatieven is klein, aangezien er 380 gemeenten in Nederland zijn. Mogelijk staan dergelijke initiatieven nog in de kinderschoenen of zijn niet alle initiatieven gevonden. Het merendeel van deze initiatieven is pas kortgeleden gestart. De samenwerking tussen de specialistische ondersteuners en het sociale domein is nog niet in alle initiatieven optimaal. We verwachten dat deze in de komende periode verder vormgegeven wordt. Verschillende con- 


\section{Bronnenlijst van de initiatieven}

1. Contactpersoon: Gedragswetenschapper CJG Kennemerland

Website: http://cjghaarlem.nl/cjg-coaches

(4-5-2017)

Memo CJG Haarlem Inzet POH'ers Jeugd vanuit CJG, dd 1-3-2017

2. Contactpersoon: Sociaal Verpleegkundige Preventiemedewerker Midden-Groningen, GGD Groningen

Website: http://www.elann.nl/nieuws/jeugdzorgin-de-eerste-lijn (24-8-2017)

Accare kinder- en jeugdpsychiatrie. Jeugd GGZ dichtbij Samenwerking met de huisartsen. Evaluatie van jeugd GGZ dichtbij projecten (juli 2013-december 2014)

3. Contactpersoon: Adviseur Jeugd JGZ Almere Website: https://ineen.nl/nieuws/2017/06/28/ almere-jgz-teams-poortwachter-voor-dejeugdhulp/ (24-8-2017)

4. Contactpersoon: gz-psycholoog en behandelcoördinator bij Entrea

De school als vindplaats. Innovatievoorstel van de combinatie voor de gemeente Nijmegen.

Nieuwsbrief.

5. Contactpersoon: gz-psycholoog/orthopedagoog Centrum voor Jeugd en Gezin Epe

Website: https://www.captise.nl/ZorgJeugd/ ArtMID/504/ArticleID/1694/Gezondheidszorgpsycholoog-CJG-ingezet-bij-huisartsen-Epe (25-8-2017)

6. Contactpersonen: programmaleider SOH en SOJ bij Karakter, Nijmegen

Website: https://www.regionijmegenopeenlijn. $\mathrm{nl} /$ nieuws/nieuwe-initiatieven-thema-jeugd

7. Contactpersoon: gedragswetenschapper Renkum

Folder Gedragswetenschapper Jeugd Renkum

tactpersonen van initiatieven gaven bijvoorbeeld aan te streven naar samenwerkingsafspraken met andere partners in het sociale domein.

Voor zover ons bekend is van slechts een van de zeven initiatieven een evaluatie beschikbaar waarin de resultaten worden beschreven [14]. Deze evaluatie laat zien dat de inzet van een jeugd-ggz-medewerker bij een huisartsenpraktijk of CJG of lokaal team in de provincie Groningen ertoe heeft geleid dat slechts een klein gedeelte van de jeugdigen doorverwezen werd naar specialistische zorg. De overige jeugdigen werden laagdrempelig dicht bij huis geholpen. Het lijkt een goede manier om huisartsen en jeugdartsen te helpen hun poortwachtersrol te vervullen. Dit resultaat wijst erop dat deze kinderen eerder zorg hebben gekregen vanuit de basiszorg, omdat er minder verwij- zingen zijn naar specialistische zorg. Van twee andere pilots gaven de specialistische ondersteuners zelf aan tevreden te zijn over de pilot. In Nijmegen betreft dit de inzet van een SOJ onder verantwoordelijkheid van de jeugdarts. Volgens de SOJ is sprake van goede samenwerking met het sociale domein, maar is er door de kleine aanstelling (1 uur per week) geen tijd om ook zelf kortdurende hulp te bieden. In Renkum betreft het de inzet van twee gedragswetenschappers jeugd bij GGD-locaties. Deze gedragswetenschappers zien veel kinderen, jeugdigen en hun ouders (aanstelling van $1 \mathrm{fte}$ ), naar tevredenheid van de betrokkenen. De samenwerking met de JGZ is echter nog niet optimaal. Ze krijgen nauwelijks kinderen doorverwezen vanuit de JGZ.

Een voldoende grote aanstelling van de specialistische ondersteuner en goede samenwerkingsafspraken tussen partners in het sociale domein lijken de meest belangrijke aandachtspunten voor het succes van de initiatieven. Wij raden aan in de toekomst evaluaties uit te voeren die aandacht besteden aan differentiatie van de doelgroep. Welke kinderen en/of problemen hebben het meeste profijt van de inzet van een specialistische ondersteuner? En met welke samenwerkingspartners in het sociale domein kunnen ze dan het beste samenwerken?

Deze inventarisatie heeft een aantal sterke punten, waaronder de systematische aanpak bij het zoeken naar relevante initiatieven en het uitvoeren van de semigestructureerde interviews. Een beperking is dat niet alle gevonden initiatieven in Nederland meegenomen konden worden, omdat over sommige daarvan weinig informatie beschikbaar is. Daarnaast is de beschrijving van de geïncludeerde initiatieven gebaseerd op informatie door betrokken individuen en slechts zo volledig als de beschikbare documentatie toeliet.

\section{Implicaties voor beleid en onderzoek}

De in dit artikel beschreven initiatieven trachten de transformatiedoelen 'tijdig de juiste hulp op maat bieden' en 'integrale hulpvormen stimuleren' te realiseren. Onlangs is er een rapport verschenen over de eerste evaluatie van de Jeugdwet, waarin wordt beschreven in hoeverre deze transformatiedoelen gerealiseerd zijn [13]. In het rapport wordt geconcludeerd dat de transformatie grotendeels nog vorm moet krijgen. Het evaluatierapport beschrijft dat er nog geen sprake is van een verminderd beroep op gespecialiseerde hulp. De meeste gemeenten blijken wel een toename te rapporteren van de samenwerking tussen verschillende partijen uit verschillende domeinen, onder andere tussen lokale toegang tot de jeugdhulp en de JGZ. Gemeenten zien minder vaak een toename in de samenwerking van de lokale teams met de huisartsen, en tussen lokale teams en specialistische jeugdhulphulpaanbieders. Daarnaast wordt in het rapport over de evaluatie van de Jeugdwet aangegeven dat de 
inzet van de $\mathrm{POH}$-jeugd kan leiden tot minder verwijzingen naar de specialistische ggz en dat verschillende gemeenten hier ook op inzetten [13].

\section{Conclusie}

De evaluatie van de Jeugdwet laat samengevat zien dat de transformatiedoelen aan het begin van 2018 nog niet gerealiseerd zijn. Initiatieven waarbij een (specialistische) jeugdhulpverlener ingezet wordt bij basiszorginstellingen of basisvoorzieningen zijn veelbelovend als het gaat om het realiseren van de transformatiedoelen. Dit kan er namelijk voor zorgen dat kinderen tijdig de passende zorg geboden wordt en dat de samenwerking met het sociale domein gestimuleerd wordt. Volgens onze inventarisatie worden er in Nederland nog maar weinig van dergelijke initiatieven uitgevoerd, wat vooral geldt voor initiatieven die gericht zijn op een bredere samenwerking in het sociale domein. Deze initiatieven zijn bovendien nauwelijks beschreven of geëvalueerd. Uitbreiding van het aantal van deze initiatieven of verbreding van $\mathrm{POH}$-initiatieven (breder dan de huisartszorg), waarbij structurele samenwerking in het sociale domein wordt beoogd, is wenselijk om bij te dragen aan de realisatie van de transformatiedoelstellingen. Evaluatieonderzoek naar de effecten van deze initiatieven is noodzakelijk. Het door ZonMw gefinancierde project 'Inzet van de Specialistisch Ondersteuner Jeugd (SOJ) in de jeugdgezondheidszorg (JGZ)' kan hiertoe bijdragen. In dit project worden twee pilots (Nijmegen en Renkum), zoals beschreven in de inventarisatie, geëvalueerd.

\section{Literatuur}

1. Dijken Kvan, Schilder A. Handreiking regionale samenwerking sociaal domein. Den Haag: Platform 31;2013.
2. Yperen T van, Wijnen B, Hageraats R. Evaluatie Jeugdwet. Meer kwaliteit en minder zorgen. Utrecht: Nederlands Jeugd Instituut; 2016.

3. Rooijen M. Samen om het kind: de handen ineen voor specialistische jeugdhulp. Utrecht: NJI; 2017.

4. Sytema S, Gunther N, Reelick F, et al. Verkenningen in de kinderen Jeugdpsychiatrie. Een bijdrage uit de psychiatrische casusregisters. Utrecht: Trimbos-instituut; 2006.

5. Gezondheidsraad. Psychische gezondheid en zorggebruik van migrantenjeugd. Publicatienr. 2012/14. Den Haag: Gezondheidsraad; 2012.

6. Boon A, Haan A de, Boer S de. Verschillen in etnische achtergrond van forensische en reguliere jeugd-ggzclienten. Kind Adolesc. 2010;31(1):16-28.

7. Boon A, Haan A de, Boer S de. Te weinig kinderen van niet-westerse herkomst komen in de Jeugd-GGZ: cijfermatige onderbouwing van een maatschappelijk probleem. Tijdschr Orthop. 2011;50:181-90.

8. Vollebergh WAM, Graaf R de, Have M ten, et al. Psychische stoornissen in Nederland: overzicht van de resultaten van Nemesis. Utrecht: Trimbos-instituut; 2003.

9. Crone MR, Bekkema N, Wiefferink CH, et al. Professional identification of psychosocial problems among children from ethnic minority groups: room for improvement. JPediatr. 2010;156(2):277-84.

10. Reijneveld SA, Veenstra R, Winter AF de, et al. Area deprivation affects behavioral problems of young adolescents in mixed urban and rural areas: the TRAILS study. J Adolesc Health. 2010;46(2):189-96.

11. Jonker T, Knot-Dickscheit J, Huyghen A. De Praktijkondersteuner Huisarts-Jeugd. Een verkennende studie. Groningen: Rijksuniversiteit;2017.

12. Otten E, Geuijen P, Zwaanswijk M et al. Specialistische ondersteuner huisartsenzorg jeugd-GGZ (SOH-JGZ). Bijblijven 2018;34:596-615.

13. Friele RD, Bruning MR, Bastiaanssen ILW, et al. Eerste evaluatie Jeugdwet. Na de transitie nu de transformatie. Den Haag: ZonMw; 2018.

14. Serra M, Drent C, Jagersma D, et al. Evaluatie van jeugd GGZ dichtbijprojecten. Groningen: Accare \& Molendrift; 2014. 